\title{
Facilitators and barriers to holistic practice, an osteopathic perspective
}

\begin{abstract}
The purpose of this mini-review is to share some insights from this author's original grounded theory research about what factors in Osteopathic participants' education most contributed to their holistic practice and which factors most impeded its development. It is hoped that by sharing these insights that some of the "missing elements' of a holistic view (i.e. those most helpful to achieving better patient outcomes as well as practitioner understanding and satisfaction) can be recognised and added back into the modern education, not only within Osteopathic education but in all health fields for the simple fact that a holistic integrated approach can potentially benefit all professions equally.
\end{abstract}

Keywords: holism, osteopathy, facilitators, barriers, healthcare, holistic education, biomedicine
Volume II Issue I - 2018

PaulWD Turner

School of Health Sciences, RMIT University, Australia

Correspondence: Paul WD Turner, School of Health Sciences, RMIT University, 47 Silverton Drive, Ferntree Gully,Victoria 3I56, Australia, Tel 6I 3 87367077,+6| 4I7I I0755,

Email paulturner@iprimus.com.au

Received: February 05, 2018 | Published: February 19, 2018

\section{Abbreviations: CAM, complementary and alternative medicine}

\section{Introduction}

In 2014 this author undertook grounded theory research investigating the meaning of Holism to experienced Osteopathic practitioners in Melbourne, Australia with the goal of developing a comprehensive theoretical framework of holism which bridges the gap between the concept of holism and its practical implementation as well as explain the relationship between holistic and biomedical approaches to health care. ${ }^{1}$ The key details of this research can be located in article titled "Holism in Osteopathy - Bridging the gap between concept and practice: A grounded theory study". ${ }^{2}$ A summary of the framework was later published in a mini-review titled "A Theoretical Framework of Holism in Healthcare". ${ }^{3}$

A key theme of this research was that understanding the framework of holism required a knowledge of two key relationships between;

i. The pathology or tissues manifesting symptoms and the symptoms themselves and

ii. Everything else going on in a person's life (be it spiritual, psychological, social, environmental, related to past trauma and/or any other component of the whole person involved) and the tissues causing symptoms (coded the "what else"). ${ }^{2}$

This "what else" (i.e. the relationships comprising the underlying problem patterns) may cause, contribute to and/or maintain the pathology/tissues causing symptoms or otherwise interfere with the body's natural self-healing mechanisms and thus impede optimal recovery. ${ }^{2}$ Understanding these relationships as well as being able to recognise clues to dysfunction manifesting in the body which identify these underlying problem patterns (the 'what else') was the key to bridging the gap;
i. between holistic concept and practice
ii. between holistic and biomedical approaches as well as
iii. offering important insights into understanding and treating

patients with a range of health issues, especially those with chronic health issues. ${ }^{2}$

As a practitioner's background education and life experiences are essential to learning how to practice holistically, the purpose of this mini-review is to share some insights from this author's original research about what factors in participants education most contributed to their holistic practice and which factors most impeded its development. ${ }^{1}$ It is hoped that by sharing these insights that some of the 'missing elements' of a holistic view (i.e. those most helpful to achieving better patient outcomes as well as practitioner understanding and satisfaction) can be recognised and added back into the modern education, not only within Osteopathic education but in all health fields for the simple fact that a holistic integrated approach can potentially benefit all professions equally.

\section{Discussion}

It is suggested by some authors that integrating biomedical and holistic approaches is required for improving health care outcomes. ${ }^{4-6}$ However, despite the concept of holism being present within the minds of many practitioners (in any health profession), there are concerns about the implementation of holism in today's world, given a biomedical emphasis in modern education (and research) and its tendency to compartmentalise information and to emphasise the part with symptoms rather than the whole person with the disease (i.e. practice in a more reductionist model). Some authors, express concerns by CAM practitioners that integration and would result in a biomedical dominance where the holistic philosophical elements are lost, either a) by bio-medicine incorporating and using CAM techniques (which often have a holistic philosophical application) in and 'add on' or 'symptomatic' way (rather than in an inter-related holistic way) or alternatively, by CAM practitioners, in their attempt to gain acceptance and legitimisation in the eyes of science and bio-medicine, incorporating biomedically dominated principles and losing their identity by practicing in a biomedical way. ${ }^{7,8}$ This begs the question - "How can we integrate holism without losing it in biomedicine?"

Participants in this authors study ${ }^{1,2}$ also indicated there was 
a biomedical regionally focused emphasis to their education but felt that both biomedical and holistic elements are essential to a holistic understanding and practice. Osteopathy was identified to have both holistic philosophical and biomedical elements involved in the education process. Participants indicated that the biomedical and regional subjects were covered very well and carried through and integrated throughout the undergraduate Osteopathic course to a high level of understanding and practice. However, the holistic philosophical and general holistic screening examination elements (for the 'what else') was 'taught of' but were not followed through, practiced and integrated, throughout the whole course to a deep practical level of understanding unless an individual lecturer could implement biomedical knowledge in a deep inter-related way and thus give students not only an understanding of symptoms and conditions but also how these problems came to be and how to read the body to be able to understand the underlying problem patterns essential to giving (palpable) history, background and context to the presenting complaint. Also, categories of knowledge (including regional assessment processes) were indicated to be primarily taught in a compartmentalised manner. The inter-relationships between the categories of knowledge on a practical clinical level (between the 'what else' and the symptomatic tissues') were thus also not explored to the same depth as were the parts themselves. As a result of a compartmental emphasis, assessments and treatments tended to be likewise compartmentalised and guided more by 'text book knowledge' rather than by feeling, knowing awareness (or mindful of what the bodies tissues were actually showing them - through observation and feeling of asymmetry -A, quality/range of motion $\mathrm{R}$, and tissue texture - $\mathrm{T}$ )

Thus, although the biomedical elements of the course we identified as essential to holistic understanding, the biomedical emphasis (in its reductionist form) paradoxically, was also identified by participants as being the biggest 'Barrier' to holistic integrated learning. Other similar and linked reasons included being limited by any particular framework or modality of practice or by a particular level/sub-level of practice (e.g. focusing only on the musculoskeletal system or part thereof), not having time or motivation to explore deeper or even being open to it. ${ }^{1}$

When asked what were the key factors that most influenced the development of a holistic understanding and which had the most impact on understanding how to treat (particularly chronic) patients well and with better success and job satisfaction, participants reported some of the key reasons to be as follows (1);

i. Motivation - wanting to help people and search for the deeper causes for their health issues.

ii. Being open minded to new information, to change preconceived viewpoints and explore everything, constantly questioning and relating everything.

iii. Learning from one's mistakes, after getting caught in a compartmentalized approach - realizing that patients are not 'text book' and that the symptomatic viewpoint doesn't work (especially for clients with chronic health issues), getting it wrong and having to expand the viewpoint to take in more variables in the whole person and their world environment and developing good general screening procedures.

iv. Having to expand the viewpoint to overcome personal and/ or family health issues (when traditional medicine had been unable to help) v. Self-reflection, reading and study - revisiting holistic philosophy and principles, early exposure to holistic principles, having good support networks, choosing post graduate studies that supported a holistic approach and studying other holistic health modalities.

vi. Interacting with teachers, Osteopathic and other professionals who can practice and teach in a holistic integrated manner and have a different way of looking at things (i.e. good mentoring).

vii. Learning how to listen and trust one's intuition and the clues within/from the body, from assessment.

It emerged from the study that these were the factors which most helped participants to understand holism. However, participants did not get this primarily from their undergraduate education, unless they were lucky enough to have access to good teachers who could teach in an integrated manner. They had to learn these things for themselves post graduate. It was indicated that if some of these elements were taught and carried through throughout the whole course then they would have been more prepared for practice and wouldn't have had to spend many years having to figure it all out the hard way on their own. The holistic and biomedical approaches eventually came to be more balanced and not contrary to one another.

\section{Conclusion}

The implications of participants' insights are in this authors opinion profound. If the factors most influencing success, happiness and understanding in practice (i.e. the understanding of the interrelationship between categories of information, general assessment processes for uncovering the 'what else' and holistic philosophical guiding principles) are not consciously taught and integrated practically throughout a course of study, then in order to achieve a balanced emphasis they need to be reintroduced, where possible, into the education as well as into future research. This however is not an easy thing to do as research often needs to be completed before it is accepted into any educational program. However, to do research at all - it needs to be based on sound holistic principles and be conducted in a holistic integrated way.

To address the barriers (i.e. a narrowly focused compartmentalised biomedical approach) and encourage the facilitators in holistic (integrated biomedical) practice the following elements are suggested for future education and research purposes by this author;

$1^{\text {st }}$ - there must be an adequate theoretical framework of holism (provided by this authors original research) $(2,3)$

$2^{\text {nd }}-$ practitioners and educators require education in this model and how to practically integrate it to the point where they can reliably gain meaningful holistic information from the body - and thus be able to see it, feel it, know it and teach it.

$3^{\text {rd }}-$ once the previous two steps are followed, research can be done to test this model, both educationally and practically, in terms of achieving improved patient outcomes, particularly in the area of chronic health.

\section{Acknowledgements}

A final implication in education is that the value of individual lecturers and the contribution they make to student understanding cannot be measured by academic knowledge alone. A real practical integrative understanding is also needed. 


\section{Conflict of interest}

The author declares no conflict of interest.

\section{References}

1. Turner P. Holism in [Osteopathic] Health Care. Melbourne, Australia: RMIT Health Sciences; 2014.

2. Turner PWD, Holroyd E. Holism in Osteopathy - Bridging the gap between concept and practice:A grounded theory study. International Journal of Osteopathic Medicine. 2016;22:40-51.

3. Turner P, Holroyd E. A theoretical framework of holism in healthcare. Insights in Biomedicine. 2017;2(1:3).

4. Heusser P, Scheffer C, Neumann M, et al. Towards non-reductionistic medical anthropology, medical education and practitioner-patientinteraction: the example of Anthroposophic Medicine. Patient Educ Couns. 2012;89(3):455-460
5. Ross CL. Integral Healthcare: the Benefits and challenges of integrating complementary and alternative medicine with a conventional healthcare practice. Integr Med Insights. 2009;4:13-20.

6. Strandberg EL, Ovhed I, Borgquist L, et al. The perceived meaning of a (w) holistic view among general practitioners and district nurses in Swedish primary care:a qualitative study. BMC Fam Pract. 2007;8:8.

7. Weise M, Oster C, Pincombe J. Understanding the emerging relationship between complementary medicine and mainstream health care:A review of the literature. Health. 2010;14(3):326-342.

8. Hill F. Health promotion and complementary medicine:The extent and future of professional collaboration and integration. Health Education. 2006;106(4):281-293. 